\title{
Simulação numérica e dimensionamento pelo MRD de pilares aparafusados de perfis formados a frio sob falha distorcional
}

\author{
Warlley Santos ${ }^{1}$, Alexandre Landesmann ${ }^{1 *}$ e Dinar Camotim ${ }^{2}$ \\ ${ }^{1}$ Programa de Engenharia Civil, COPPE, Universidade Federal do Rio de Janeiro, \\ Av. Horácio Macedo 2030, Ilha do Fundão Rio de Janeiro - RJ, Brasil, \\ warlley.soares@coc.ufrj.br / alandes@coc.ufrj.br \\ ${ }^{2}$ CERIS, ICIST, DECivil, Instituto Superior Técnico, Universidade de Lisboa, Av. \\ Rovisco Pais 1049-001 Lisboa, Portugal, dcamotim@civil.ist.utl.pt
}

\begin{abstract}
Resumo
O artigo reporta uma investigação numérica sobre o comportamento e resistência última de pilares de perfil formado a frio de seção transversal tipo $U$ enrijecido com extremidades aparafusadas selecionadas para falharem sob modo distorcional. O modelo numérico é usado em análise paramétrica envolvendo pilares com diversas combinações de geometria (comprimento e dimensões de seção transversal) e material com comportamento elásticoplástico perfeito (resistência ao escoamento), objetivando adquirir conhecimento sobre o mecanismo pós-crítico e gerar dados de resistência última. Finalmente, os dados de resistência última obtidos são usados para avaliar a qualidade das previsões pelo MRD da atual curva de dimensionamento distorcional e, se necessário, propor preliminarmente diretrizes de como melhora-la.
\end{abstract}

Palavras-chave: pilares em perfil formado a frio com extremidades aparafusadas, falha distorcional, investigação numérica e Método da Resistência Direta (MRD).

\section{Introdução}

Perfis Formados a Frio (PPF) são largamente usados pela indústria da construção civil pelo fato de possuir alta eficiência estrutural (relação resistência / peso), baixo custo de produção e notável versatilidade de fabricação. Com o uso de aços mais resistentes e perfis com espessura de parede cada vez mais fina, os engenheiros lidam inevitavelmente com problemas complexos de dimensionamento, particularmente no campo de estabilidade estrutural e ligações (Rondal, 2000). Uma consequência imediata desta tendência é o crescimento de inadequações dos métodos tradicionais empregados para dimensionamento de barras de PFF propensas a deformações em plano dos 
componentes da seção transversal, que se baseia no conhecido amplamente aceito conceito do Método da Largura Efetiva (Landesmann and Camotim, 2013).

Para superar esta limitação Schafer (2008) propôs o Método da Resistência Direta (MRD) que teve origem no trabalho de Hancock et al. (1994). Devido à sua simplicidade, o MRD foi incorporado na norma brasileira ABNT NBR 14762 (2010), na norma americana AISI-S100 (2016) e na australiana / nova zelandeza AS/NZS 4600 (2005) como um método alternativo ao Método da Largura Efetiva. A principal vantagem do MRD é a sua facilidade de dimensionamento e a capacidade de explicar com precisão o comportamento de seções complexas (Pham et al., 2013). O MRD baseia-se na ideia de que se o engenheiro consegue determinar todas as forças axiais de instabilidade elástica de um pilar, i.e. instabilidade local $\left(P_{c r . L}\right)$, distorcional $\left(P_{c r . D}\right)$ e global $\left(P_{c r . e}\right)$, e também a força que causa escoamento da seção $\left(P_{y}\right)$, então a resistência pode ser diretamente determinada, i.e., $P_{n}=f\left(P_{c r . L}, P_{c r . D}, P_{c r . e}, P_{y}\right)$ (Schafer, 2008).

Segundo o MRD, a resistência de um pilar é a menor das três forças nominais: global $\left(P_{n . e}\right)$, distorcional $\left(P_{n . D}\right)$ e interação local/global $\left(P_{n . L e}\right)$. Essas forças nominais são fornecidas pelas expressões:

$$
\begin{aligned}
& P_{n . e}=\left\{\begin{array}{l}
\left(0,658^{\bar{\lambda}_{e}^{2}}\right) P_{y} \text { se } \bar{\lambda}_{e} \leq 1,5 \\
\left(0,877 / \bar{\lambda}_{e}^{2}\right) P_{y} \text { se } \bar{\lambda}_{e}>1,5
\end{array}\right. \\
& P_{n . D}=\left\{\begin{array}{l}
P_{y} \text { se } \bar{\lambda}_{D} \leq 0,561 \\
P_{y}\left[1-0,25\left(P_{c r . D} / P_{y}\right)^{0,6}\right]\left(P_{c r . D} / P_{y}\right)^{0,6} \text { se } \bar{\lambda}_{D}>0,561
\end{array}\right. \\
& P_{n . L e}=\left\{\begin{array}{l}
P_{n . e} \text { se } \bar{\lambda}_{L . e} \leq 0,776 \\
P_{n . e}\left[1-0,15\left(P_{c r . L} / P_{n . e}\right)^{0,4}\right]\left(P_{c r . L} / P_{n . e}\right)^{0,4} \text { se } \bar{\lambda}_{L . e}>0,776
\end{array}\right.
\end{aligned}
$$

onde $P_{y}$ é a força de escoamento da seção e $\bar{\lambda}_{e}=\left(P_{y} / P_{c r . e}\right)^{0,5}, \quad \bar{\lambda}_{D}=\left(P_{y} / P_{c r . D}\right)^{0,5}$ e $\bar{\lambda}_{L . e}=\left(P_{n . e} / P_{c r . L}\right)^{0,5}$ representam o índice de esbeltez reduzido à instabilidade global, distorcional e interação local/global (Schafer, 2008). 


\subsection{Motivação}

De acordo com Yu e Panyanouvong (2103), somente conexões chapa a chapa foram ensaiadas. Entretanto, a indústria da construção civil tem usado extensivamente ligações aparafusadas em PFF. Um exemplo de montagem de treliças com conexões aparafusadas é ilustrado na Figura 1(a) e (b), respectivamente.

Por outro lado, ensaios de compressão em pilares de PFF são realizados com chapas rígidas soldadas nas suas extremidades ${ }^{1}$. Além do mais, as expressões do MRD foram calibradas com resultados de ensaios experimentais tendo em sua maioria pilares engastados (placas rígidas soldadas nas extremidades dos pilares) (Schafer, 2000). Apesar de Schafer mencionar que "estas foram testadas na condição pinada", esta afirmação diz respeito ao comportamento global do pilar (a placa rígida usualmente sobre rótula esférica ou cilíndrica) - tão quanto o comportamento distorcional é considerado engastado (Landesmann and Camotim, 2013).

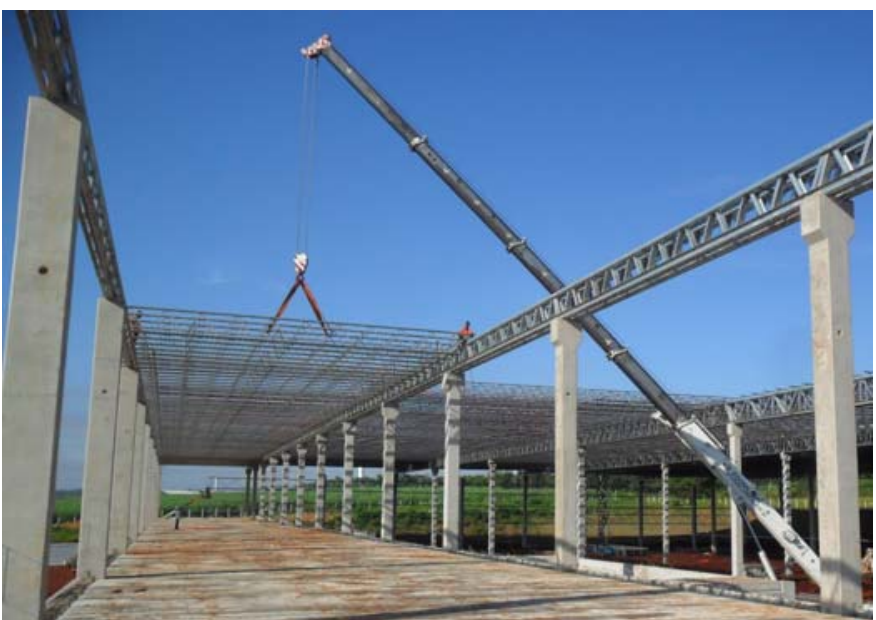

(a)

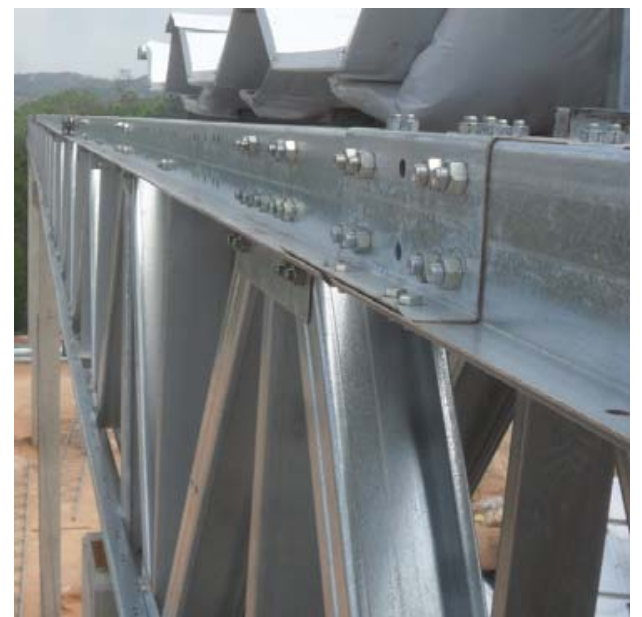

(b)

Figura 1 - (a) Montagem de treliças e (b) ligações aparafusadas em barras de PFF.

Em adição, uma investigação numérica conduzida por Landesmann e Camotim (2013) sobre pilares de PFF com condição de extremidade simplesmente apoiada demonstrou que a atual curva de dimensionamento distorcional do MRD não é capaz de prever adequadamente a resistência de pilares com condição de extremidades diferente da

\footnotetext{
${ }^{1}$ De fato, não é fácil ensaiar pilares com extremidade diferente da engastada (e.g., pilar simplesmente apoiada) que falham no modo distorcional - é extremamente difícil garantir que a seções extremas do pilar fiquem livres para empenar (Landesmann e Camotim, 2013).
} 
engastada. Como principal resultado, Landesmann e Camotim (2013) propuseram modificação na curva de dimensionamento distorcional do MRD definida pela Eq. (4) recomendada para uso em pilares do tipo $U$ enrijecido, cartola, rack e $Z$ simplesmente apoiadas.

$$
P_{n . D}^{*}=\left\{\begin{array}{l}
P_{y} \text { se } \bar{\lambda}_{D} \leq 0,561 \\
P_{y}\left[1-0,25\left(P_{c r . D} / P_{y}\right)^{0,6}\right]\left(P_{c r . D} / P_{y}\right)^{0,6} \text { se } 0,561<\bar{\lambda}_{D} \leq 1,133 \\
P_{y}\left[0,65-0,2\left(P_{c r . D} / P_{y}\right)^{0,75}\right]\left(P_{c r . D} / P_{y}\right)^{0,75} \text { se } \bar{\lambda}_{D}>1,133
\end{array}\right.
$$

A falta (pelo menos para o conhecimento dos autores) de pesquisas sobre pilares aparafusadas sujeitas à flambagem distorcional, o constante uso de ligações aparafusadas em construções com PFF e os resultados derivados da pesquisa previamente mencionada de Landesmann e Camotim (2013) constituem a motivação para o estudo exposto neste artigo.

\subsection{Objetivos}

O objetivo deste trabalho é avaliar a qualidade das previsões de resistência fornecidas pela atual curva de resistência distorcional do MRD em pilares de aço de perfis formados a frio com extremidades aparafusadas normalmente empregadas na indústria de construção brasileira considerando as seguintes características:

i. Pilares de perfis formados a frio tipo $U$ enrijecidos flambando no modo distorcido "puro", tanto quanto possível, e exibem colapso distorcional.

ii. Extremidades aparafusadas.

iii. Diferentes classes de aço.

\section{Modelo de Elementos Finitos}

A condição parafusada é caracterizada pela ligação de dois parafusos montados em furos nas mesas (veja Figura 2(a)) cujos os centros são devidamente localizados sobre o eixo de menor inércia da seção transversal e estão distantes de $35 \mathrm{~mm}$ da extremidade livre do perfil. O diâmetro do parafuso considerado neste trabalho foi $20 \mathrm{~mm}$, o 
diâmetro do furo $d_{f}=21,5 \mathrm{~mm}$, sendo que um par de arruelas lisas (com $37 \mathrm{~mm}$ diâmetro externo e $3 \mathrm{~mm}$ de espessura) foi considerado "soldado" em cada uma das mesas do perfil, internamente e externamente a essas mesas, com o objetivo de prevenir falha localizada nos furos.

As trajetórias de equilíbrio pós-crítica e resistência última foram determinadas por meio de análises não lineares (geometria e material) pelo método dos elementos finitos realizadas no programa ANSYS (2009). Os pilares foram discretizadas usando-se o elemento SHELL181 (nomenclatura do ANSYS - 4-nós elementos de casca com seis graus de liberdade por nó, integração completa e degeneração em elemento triangular) - a dimensão máxima do elemento foi considerada como $5.3 \mathrm{~mm}$ - estudos de convergência demonstrados em Santos (2017).
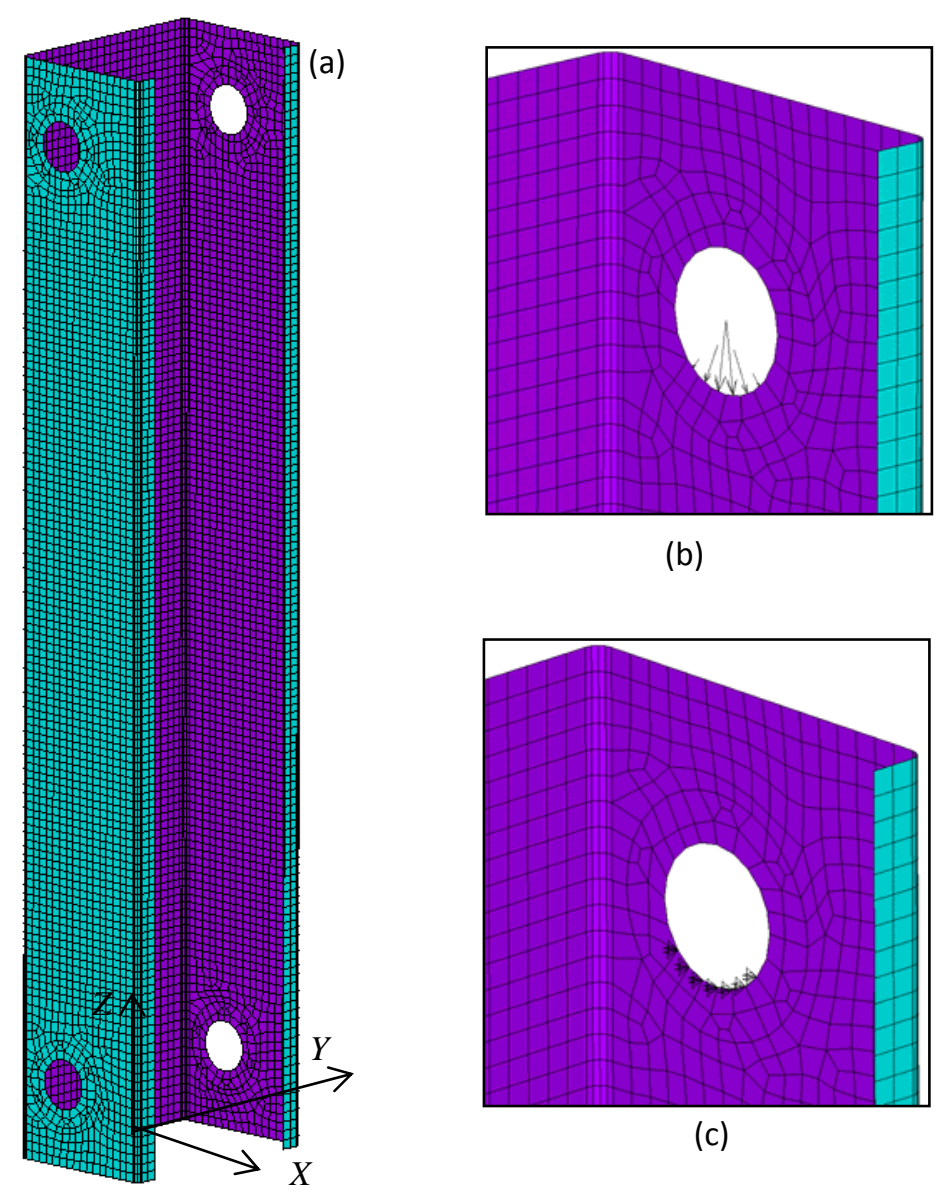

(b)

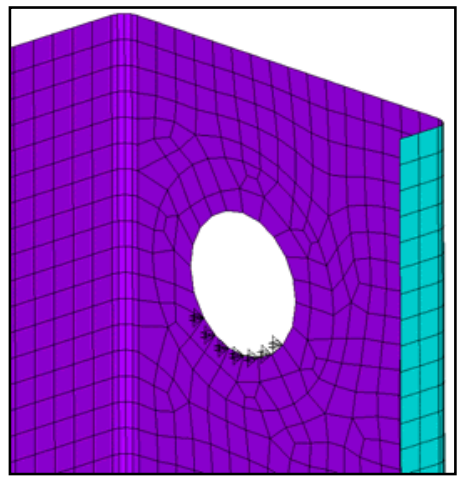

(c)

Figura 2 - Modelo de elementos finitos: (a) malha, (b) carregamento e (c) condição de contorno. 
Para o carregamento por contato, uma pressão na linha de contato (parafuso-furo) foi considerada (veja Figura 2(b)). Estudos numéricos (Santos, 2017) mostraram que o ângulo formado pelo setor circular do contato é aproximadamente $\alpha=97,2^{\circ}$ (1,696 rad.) e que a distribuição do carregamento pode ser considerada como um gradiente linear que decresce sua intensidade do centro para as extremidades, sendo nas extremidades nulo (Santos, 2017). As condições de contorno adotadas foram a restrição dos deslocamentos na direção $X$ e $Y$ nas linhas de contato parafuso-furo (veja Figura 2(c) em ambas as extremidades) e o ponto central (nó) da alma teve seu deslocamento na direção $Z$ restringido.

As analises foram desenvolvidas considerando $E=20500 \mathrm{kN} / \mathrm{cm}^{2}$ (modulo de Young) e $v=0,3$ (coeficiente de Poisson) desenvolvidas em duas etapas: análise de flambagem e pós-crítica.

$\mathrm{Na}$ análise de flambagem é possível estimar a força de flambagem elástica e avaliar qualitativamente a forma da deformada relacionadas a esta força.

Todas as análises pós-críticas foram realizadas por meio de técnica incremental-iterativa combinando o método de Newton-Raphson com a estratégia de controle de comprimento de arco, onde as forças axiais são sempre acrescidas de um pequeno incremento, utilizando o procedimento automático do ANSYS (2009). Nas análises, também foi considerado um material elastoplástico perfeito. Diferentes graus de aços $\left(f_{y}\right)$ foram incorporados nos modelos numéricos dos pilares com o objetivo de adquirir mais dados de resistência última. Não foram considerados nas análises tensões residuais e tampouco o efeito de encruamento devido ao trabalho de conformação a frio do perfil ${ }^{2}$.

A imposição das imperfeições geométricas equivalentes iniciais do modo crítico nos pilares foi feita automaticamente por meio do procedimento a seguir: determinação da forma do modo crítico de instabilidade, através de análise de flambagem no ANSYS, que se adota exatamente a mesma discretização/malha empregada para realizar a subsequente análise pós-crítica, que foi então escalada para exibir um deslocamento

\footnotetext{
${ }^{2}$ De acordo com Schafer (1998) em modelos numéricos se as tensões residuais são ignoradas, então a elevação da resistência ao escoamento devido ao trabalho a frio de formação da seção também não deve ser incluída.
} 
distorcional máximo ao longo dos enrijecedores de borda igual a 0,1t (Landesmann e Camotim, 2013).

As análises pós-crítica são subdivididas em elástica e elastoplástica.

Analisando-se as trajetórias de equilíbrio elásticas de pilares parafusadas é possível determinar o modo de instabilidade (se distorcional ou não). Adicionalmente, tais trajetórias de equilíbrio explicam qual a imperfeição geométrica inicial, se com as mesas "fechando" ou "abrindo", resulta a trajetória de equilíbrio mais abaixo.

Nas análises pós-crítica elastoplástica os principais resultados são as trajetórias de equilíbrio e a resistência última.

Os modelos numéricos foram calibrados comparando os resultados numéricos com ensaios realizados no Laboratório de Estruturas da COPPE/UFRJ, os mesmos são reportados em Santos (2017).

\section{Seleção da Geometria dos Pilares}

O primeiro passo deste trabalho consistiu na seleção cuidadosa das dimensões da seção transversal e dos comprimentos de pilares tipo $U$ enrijecido para serem analisadas numericamente. O procedimento de seleção envolveu o método da "tentativa e erro" em análises de flambagem (de acordo com a seção 0), visando satisfazer os seguintes requisitos:

i. Pilares suscetíveis à flambagem distorcional "pura". Este objetivo é alcançado assegurando que a força crítica de flambagem é claramente distorcido e e com valor consideravelmente abaixo dos menores valores das forças de bifurcação locais e/ou globais.

ii. Dimensões de seção comumente usadas e envolvendo diferentes proporções almamesa.

Foi possível atender todos os requerimentos acima mencionados e o resultado final desta seleção são as 15 seções-transversais dadas na Tabela 1. As dimensões da seção transversal são definidas na Figura $3(a)$ - note que a relação alma-mesa $\left(b_{w} / b_{f}\right)$ varia entre $0,70,1,00$ e 1,43. A espessura de parede $(t)$, a largura do enrijecedor de borda $\left(b_{l}\right)$ 
e o raio interno $\left(r_{i}\right)$ foram considerados constantes e iguais a $2,65 \mathrm{~mm}, 10,6 \mathrm{~mm}$ e 1,325 $\mathrm{mm}$, respectivamente.

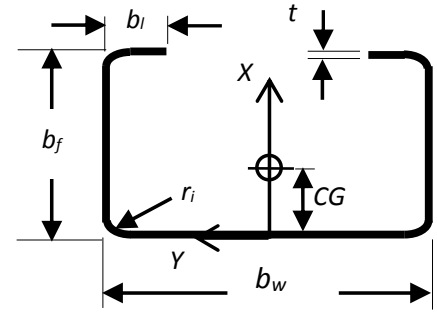

(a)

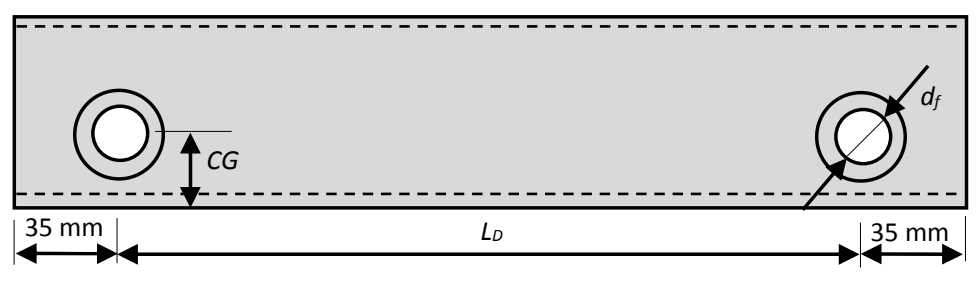

(b)

Figura 3 - (a) Seção transversal e (b) vista lateral do pilar.

A seleção do comprimento $\left(L_{D}\right)$ do pilar obedeceu ao critério: pilares cujo modo de flambagem seja o distorcional com uma semi-onda e tal comprimento deve ser um mínimo na curva $P_{c r}$ versus $L_{D}$ onde $P_{c r}$ é a força crítica de instabilidade calculada numericamente na análise de flambagem. Para cada seção diferentes comprimentos foram testados, de $10 \mathrm{~cm}$ até $1000 \mathrm{~cm}$, com $5 \mathrm{~cm}$ incremento, a Tabela 1 apresenta o comprimento associado com a força crítica distorcional de flambagem $\left(L_{D}\right)$. A Figura 4 ilustra um exemplo da determinação do comprimento da semi-onda de flambagem distorcional $L_{D}$ de uma seção. Também na Figura 4 é mostrada a deformação distorcional advinda da análise de flambagem. Ainda na Figura 4 nota-se que não se apresente um mínimo local de chapa bem definido.

A Tabela 1 também fornece, para cada pilar nomeada de acordo com as larguras da alma e da mesa, área da seção transversal $(A)$, a distância do centro de gravidade da seção até a face externa da alma $(C G)$, a força crítica (distorcional) $\left(P_{c r . D}\right)$ e as relações entre a menor força crítica local e a força crítica distorcional $\left(P_{b 1 . L} / P_{c r . D}\right)$ e a menor força crítica global com relação a força crítica distorcional $\left(P_{b 1 . e} / P_{c r . D}\right)$, indicando quão longe estas estão entre um e outra.

Observa-se na Tabela 1 que a primeira força crítica "não distorcional" corresponde sempre à força crítica de instabilidade local e que a relação $P_{b 1 . L} / P_{c r . D}$ varia entre $1,51 \mathrm{e}$ 2,07. A primeira força crítica de instabilidade global é invariavelmente maior (muito maior) do que a força crítica de instabilidade distorcional. De fato, os valores $P_{b 1 . e} / P_{c r . D}$ estão entre 6,93 e 72,0. 
Tabela 1 - Dimensões, área e posição do centro de gravidade da seção, comprimento, força crítica de instabilidade distorcional e relações força crítica local e global em relação a força crítica distorcional.

\begin{tabular}{l|ccccc|ccc}
\hline \multicolumn{1}{c|}{ Pilares } & $\begin{array}{c}b_{w} \\
(\mathrm{~mm})\end{array}$ & $\begin{array}{c}b_{f} \\
(\mathrm{~mm})\end{array}$ & $\begin{array}{c}A \\
\left(\mathrm{~cm}^{2}\right)\end{array}$ & $\begin{array}{c}C G \\
(\mathrm{~mm})\end{array}$ & $\begin{array}{c}L_{D} \\
(\mathrm{~mm})\end{array}$ & $\begin{array}{c}P_{c r . D} \\
(\mathrm{kN})\end{array}$ & $\begin{array}{c}P_{b 1 . L} \\
P_{c r . D}\end{array}$ & $\frac{P_{b 1 . e}}{P_{c r . D}}$ \\
\hline $100 \times 70$ & 100 & 70 & 6,52 & 24,22 & 350 & 323 & 1,51 & 6,93 \\
\hline $100 \times 100$ & 100 & 100 & 8,11 & 37,47 & 450 & 216 & 1,81 & 8,24 \\
\hline $100 \times 142,9$ & 100 & 142,9 & 10,38 & 57,35 & 550 & 140 & 1,93 & 10,8 \\
\hline $130 \times 91$ & 130 & 91 & 8,43 & 30,39 & 450 & 236 & 1,54 & 12,1 \\
\hline $130 \times 130$ & 130 & 130 & 10,50 & 47,51 & 550 & 157 & 1,83 & 16,1 \\
\hline $130 \times 185,7$ & 130 & 185,7 & 13,45 & 73,23 & 650 & 102 & 1,97 & 24,9 \\
\hline $150 \times 105$ & 150 & 105 & 9,70 & 34,49 & 500 & 199 & 1,59 & 17,6 \\
\hline $150 \times 150$ & 150 & 150 & 12,09 & 54,19 & 600 & 132 & 1,87 & 24,4 \\
\hline $150 \times 214,3$ & 150 & 214,3 & 15,49 & 83,84 & 700 & 85.4 & 2,03 & 35,8 \\
\hline $180 \times 126$ & 180 & 126 & 11,61 & 40,64 & 550 & 160 & 1,69 & 30,8 \\
\hline $180 \times 180$ & 180 & 180 & 14,47 & 64,21 & 650 & 106 & 1,96 & 44,3 \\
\hline $180 \times 257,1$ & 180 & 257,1 & 18,56 & 99,70 & 800 & 68.6 & 2,07 & 58,6 \\
\hline $200 \times 140$ & 200 & 140 & 12,88 & 44,74 & 600 & 141 & 1,72 & 39,9 \\
\hline $200 \times 200$ & 200 & 200 & 18,06 & 70,89 & 750 & 93.8 & 1,89 & 51,6 \\
\hline $200 \times 285,7$ & 200 & 285,7 & 20,60 & 110,3 & 900 & 60.3 & 2,04 & 72,0 \\
\hline
\end{tabular}

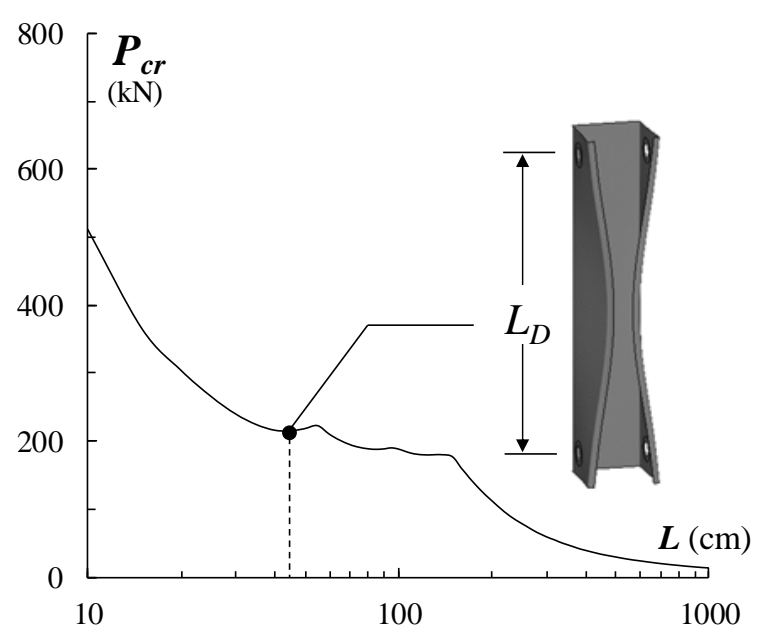

Figura 4 - Variação do valor $P_{c r}$ com função do comprimento $L$ para o pilar 100x100.

\section{Resultados Numéricos}

\subsection{Análise Pós-Crítica Elástica}

A fim de se realizar as avaliações qualitativa e quantitativa de como o comportamento pós-crítico elástico do pilar é influenciado pela condição de ligação aparafusada, trajetórias de equilíbrio elásticas pós-críticas foram obtidas.

A Figura 5 mostra as trajetórias de equilíbrio do pilar 200×200. Nestas trajetórias $P$ é a força aplicada e $|\delta|$ o deslocamento absoluto máximo que ocorre ao longo do 
enrijecedor de borda. Neste exemplo, a imperfeição geométrica inicial foi considerada a forma de flambagem crítica (distorcida) tendo como amplitude máxima o deslocamento do enrijecedor de borda de 0,1t "abrindo" e "fechando" as mesas. A observação destas duas trajetórias de equilíbrio pós-críticas distorcionais elásticas leva à conclusão de que a trajetória de equilíbrio mais baixa é sempre aquela que possui imperfeição inicial que "fecha" as mesas.

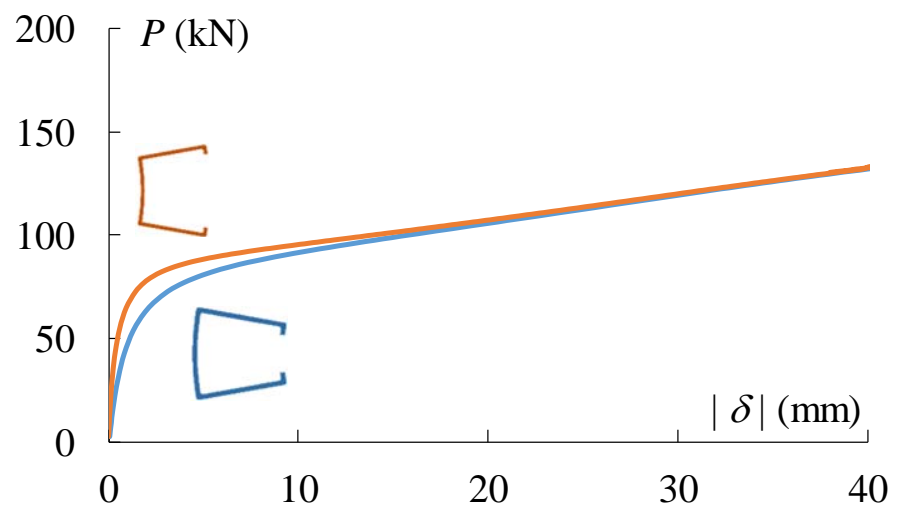

Figura 5 - Trajetória de equilíbrio elástica $P$ versus $|\delta|$ para o pilar 200×200 com imperfeição inicial distorcional "abrindo" e "fechando" as mesas.

\subsection{Análise Pós-Crítica Elastoplástica e Resistência Última}

A atenção é agora dedicada à influência qualitativa e quantitativa da condição de suporte aparafusada nos pilares no comportamento pós-crítico elastoplástico distorcional e resistência última. Nesta seção, os pilares com diferentes geometrias (dimensões e comprimentos) apresentadas na Tabela 1 são discutidas considerando o material com resistência ao escoamento $f_{y}=34,5 \mathrm{kN} / \mathrm{cm}^{2}$ e imperfeição inicial conforme forma crítica distorcional com mesas "fechando" e amplitude máxima de 0,1t.

A Figura 6 mostra exemplos de trajetórias de equilíbrio não-lineares (geométrica e de material) a fim de obter a resistência última $P_{u}$ (identificadas por círculos brancos). Essas trajetórias são relativas aos pilares 100×70, 180×126 e 200×140 onde no eixo vertical são registrados os valores da força de compressão $P$ normalizada pela força crítica de instabilidade distorcional $P_{c r . D}$ e no eixo horizontal são apresentados os valores do máximo deslocamento absoluto $|\delta|$ na direção do eixo $Y$ (veja Figura 2(a)) normalizado pela espessura de parede $t$. A Figura 7 retrata as deformações que ocorrem próximo à resistência última para cada trajetória de equilíbrio exibida na Figura 6 , sendo fornecidas 
representações bastante precisas dos modos de falha (distorção) exibidos pelos pilares $100 \times 70,180 \times 126$ e $200 \times 140$.

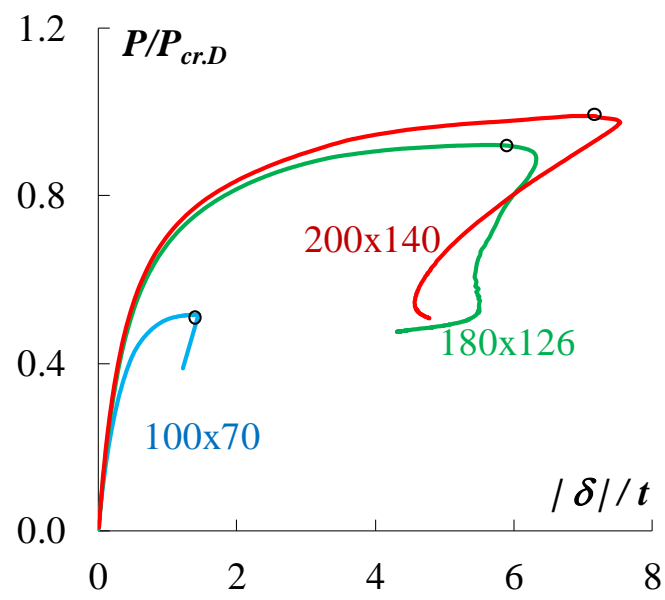

Figura 6 - Trajetórias de Equilíbrio elásto-plástica distorcional $\left(P / P_{c r . D} v s .|\delta| / t\right)$ para os

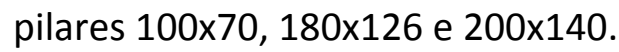
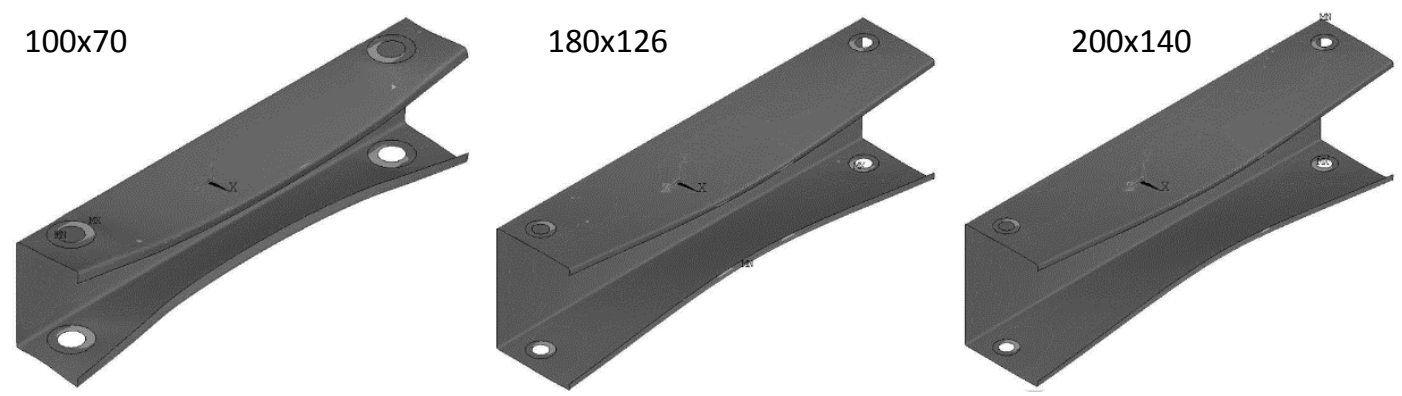

Figura 7 - Modo de falha distorcional para os pilares 100x70, 180x126 e 200x140.

A Figura 8 mostra a trajetória de equilíbrio e evolução (estágios) das deformações junto com a distribuição da tensão equivalente de von Mises equivalente para o pilar 200x140, onde no estágio I ocorre o início de escoamento especificamente próximo aos furos; com a progressão do carregamento no estágio /l apresenta-se a deformação distorcional; no estágio III inicia-se escoamento nos enrijecedores de borda no meio do pilar; finalmente no estágio $I V$ a resistência última é alcançada com a formação de uma "rótula plástica distorcional" no meio do pilar. 


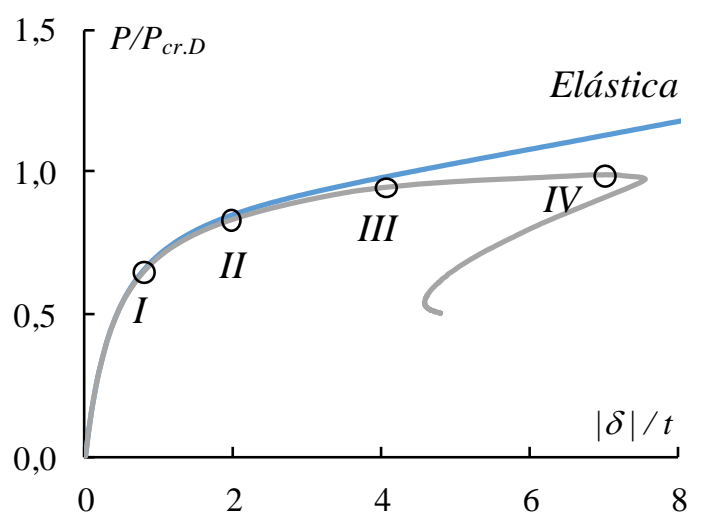

(a)

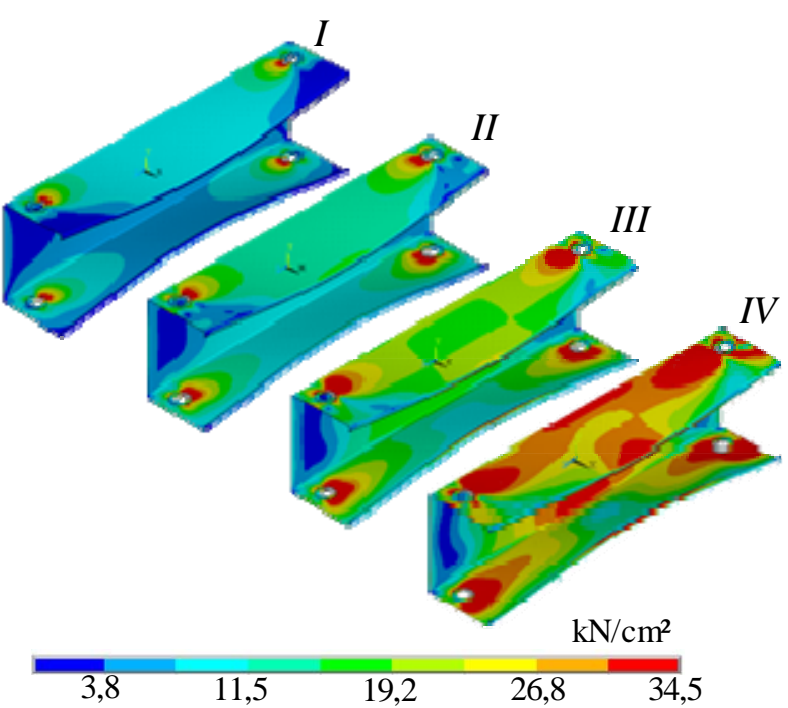

(b)

Figura 8 - (a) Trajetórias de equilíbrio elástica e elastoplastica e (b) mecanismo de colapso por flambagem distorcional para o pilar 200x140.

\subsection{Análise Paramétrica}

O objetivo desta secção é apresentar e discutir os resultados da resistência última obtidos a partir do estudo paramétrico realizado. A fim de obter uma comparação mais significativa, todos os resultados pós-críticos apresentados e discutidos nesta seção dizem respeito o pilares feitas de aço com sua esbeltez distorcional $\bar{\lambda}_{D}=\left(P_{y} / P_{c r . D}\right)^{0,5}$ variando de 0,4 até 3,5 - esta esbeltez é assegurada pela seleção adequada de tensões de escoamentos $\left(f_{y}\right)^{3}$.

O estudo paramétrico envolveu um total de 210 pilares, correspondendo a combinação de quinze pilares descritas na Tabela 1 e quatorze valores de índice de esbeltez distorcional. Todos os dados de resistência última $\left(P_{u}\right)$, forças de escoamento $\left(P_{y}=A \cdot f_{y}\right)$ e valores do índice de esbeltez distorcional $\left(\bar{\lambda}_{D}\right)$ de cada pilar são apresentados em Santos (2017). Esses valores são também plotados na Figura 9(a) onde no eixo vertical tem-se a resistência última $P_{u}$ normalizada pela força de escoamento $P_{y}$ e no eixo horizontal os valores do índice de esbeltez reduzido $\bar{\lambda}_{D}$.

Examinando o tipo de falha dos pilares plotadas na Figura 9(a) foi encontrado em algumas delas a ocorrência de falha localizada nas regiões próxima aos furos (círculos vermelhos). Na Figura 10 é mostrada uma distribuição qualitativa das tensões

\footnotetext{
${ }^{3}$ A razão para selecionar tais tensões de escoamento foi possibilitar a análise de pilares com altos valores de esbeltez, cobrindo assim um amplo alcance de esbeltez (Landesmann \& Camotim, 2013).
} 
equivalentes de von Mises para o pilar 200×285,7 cuja a falha se deu por efeitos localizados.

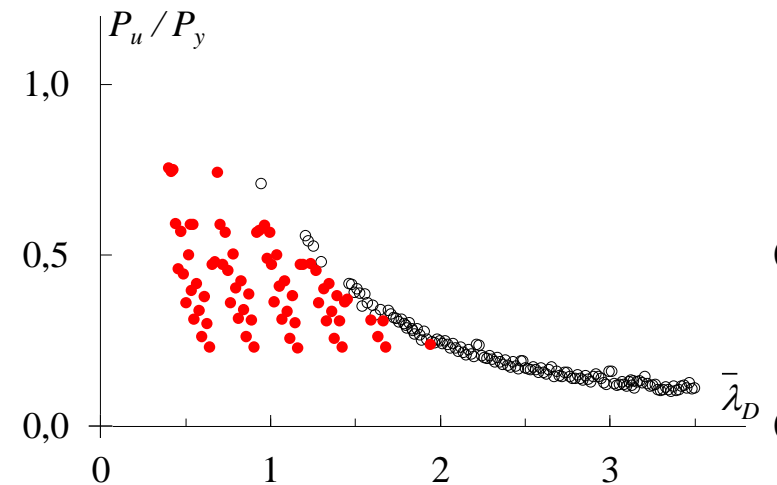

(a)

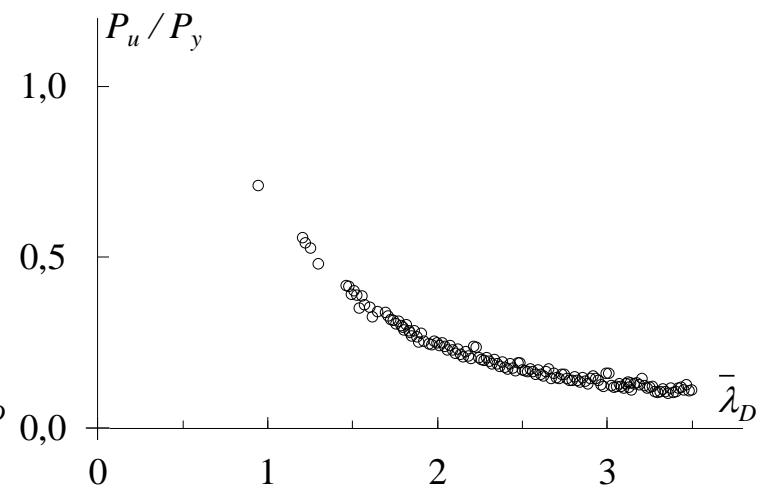

(b)

Figura 9 - Resultados numéricos $P_{u} / P_{y}$ versus $\bar{\lambda}_{D}$ para (a) todos os pilares e (b) desconsiderando os pilares cujo colapso se deu por efeitos localizados.

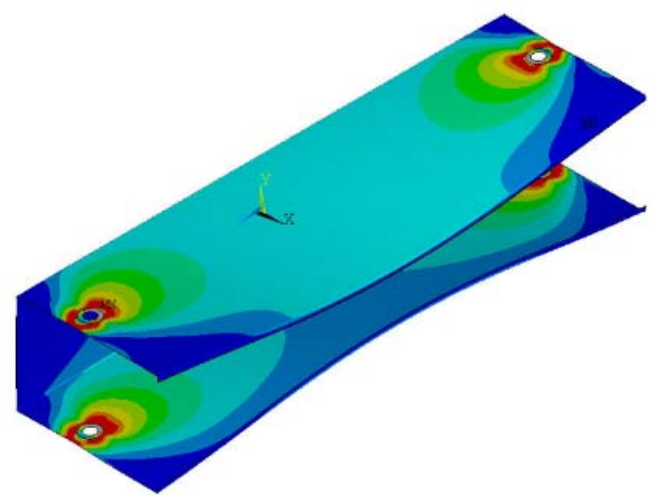

Figura 10 - Distribuição qualitativa das tensões equivalentes de von Mises no pilar $200 \times 285,7$ que apresentou falha localizada.

Como o proposito deste trabalho não é avaliar a resistência de pilares que apresentam falhas localizadas tais pilares foram exclusos da análise paramétrica. Um total de 138 pilares foi usado na análise paramétrica. Substituindo o gráfico da Figura 9(a) pela Figura 9(b) desconsiderando os pilares cujo colapso se deu por falha localizada, pode-se dizer que a "nuvem" de pontos $P_{u} / P_{y}$ vs. $\bar{\lambda}_{D}$ segue uma tendência que pode ser descrita com precisão por uma curva de dimensionamento do tipo "Winter".

\section{Considerações relativas ao MRD}

Esta secção aborda a aplicabilidade do MRD para estimar a resistência última de pilares do tipo $U$ enrijecido falhando no modo distorcional e que apresentam condição de extremidades aparafusada. O primeiro passo consiste em computar $P_{n . e}, P_{n . D}$ e $P_{n . L e}$, de 
acordo com as Eqs. (1), (2) e (3), para os 138 pilares analisadas na seção 4.3, a fim de avaliar a natureza do colapso dos pilares previstos pelo MRD - todas as predições de falha pelo MRD foram distorcional. Todas os resultados numéricos $\left(P_{c r . D}, P_{u}\right.$ e modo de falha) e valores nominais fornecidos pelo MRD $\left(P_{n . D}\right)$, juntamente com os valores do índice de esbeltez reduzido correspondentes são apresentados em Santos (2017).

A Figura $11\left(a_{1}\right)$ compara a atual curva de dimensionamento distorcional do MRD com os valores de resistência última obtidos numericamente dos perfis que deformam no modo distorcional. A Figura $11\left(b_{1}\right)$, por outro lado, mostra os valores correspondentes de $P_{u} / P_{n . D}$ versus $\bar{\lambda}_{D}$ proporcionando assim uma representação da precisão e segurança das estimativas de resistência última do MRD.

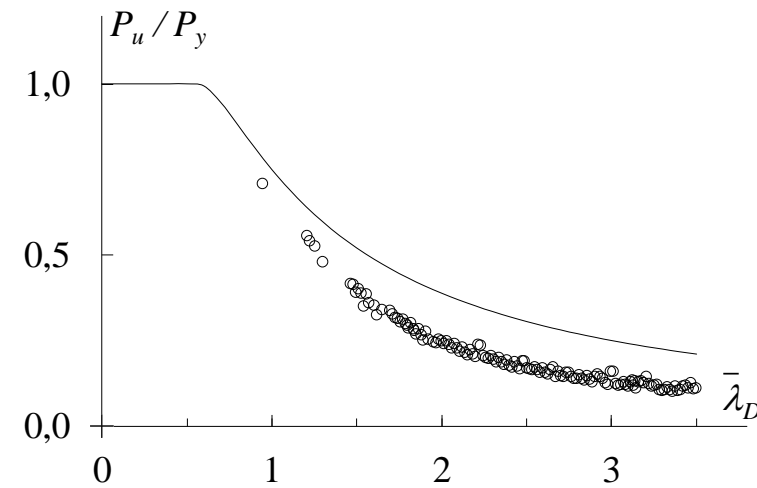

$\left(\mathrm{a}_{1}\right)$

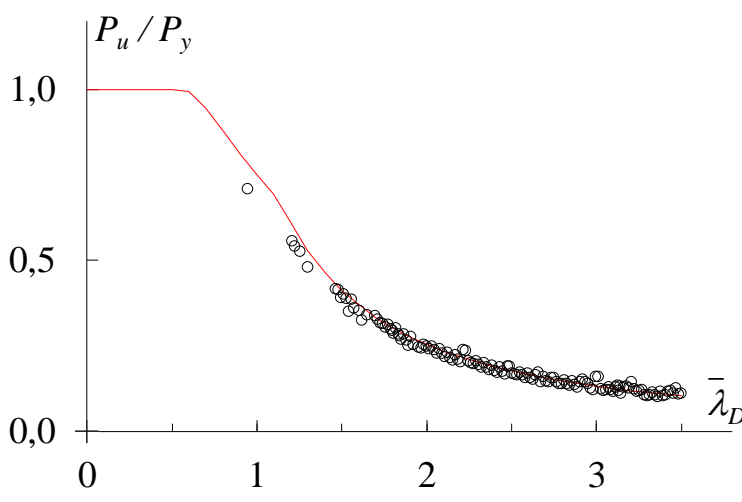

$\left(a_{2}\right)$

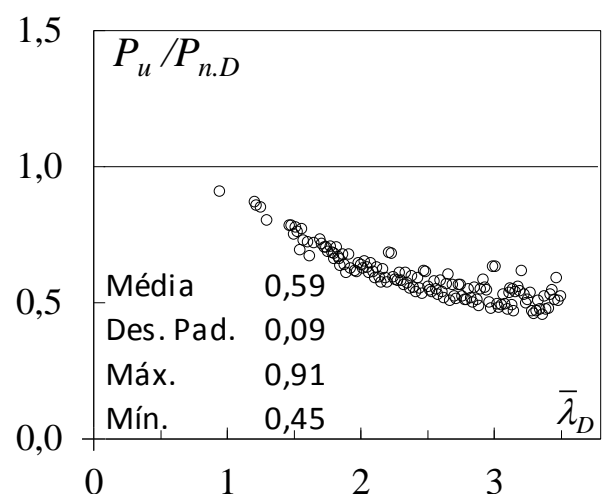

$\left(b_{1}\right)$

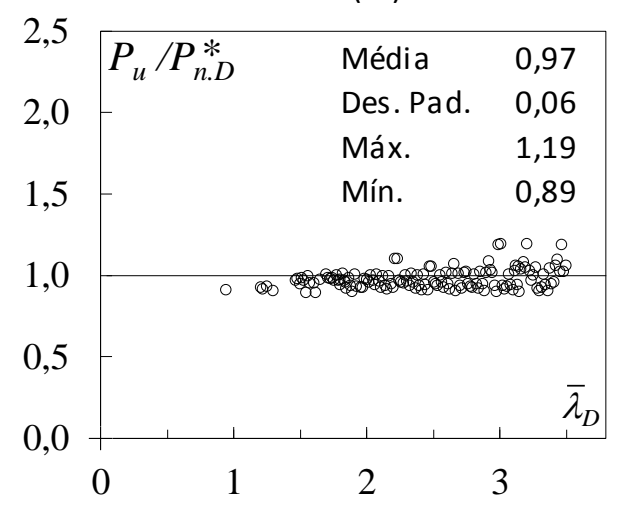

$\left(b_{2}\right)$

Figura 11 - Comparação entre resultados numéricos de resistência última com $\left(\mathrm{a}_{1}\right) P_{n . D} \mathrm{e}$ $\left(\mathrm{a}_{2}\right) P_{n . D}^{*}$ e $\left(\mathrm{b}_{1}\right) P_{u} / P_{n . D}$ versus $\bar{\lambda}_{D}$ e $\left(\mathrm{b}_{2}\right) P_{u} / P_{n . D}^{*}$ versus $\bar{\lambda}_{D}$

A observação das Figura 11( $\left.a_{1}\right)$ e $\left(b_{1}\right)$ mostra as seguintes conclusões:

i. Observa-se facilmente que as resistências últimas são excessivamente superestimadas pela curva distorcional do MRD. 
ii. Na Figura $11\left(b_{1}\right)$ nota-se o número de valores $P_{u} / P_{n . D}$ próximo (abaixo e/ou acima) de 0,5 . Este fato indica uma progressiva deterioração da qualidade das estimativas de resistência última distorcionais do MRD. A média, desvio padrão, valores máximos e mínimos da razão $P_{u} / P_{n . D}$ são apresentados na Figura $11\left(\mathrm{~b}_{1}\right)$.

Em vista dos fatos acima, pode-se afirmar que a atual curva distorcional do MRD não é adequada para aplicação em pilares cuja condição de extremidade é aparafusada. Portanto, é necessário considerar uma curva de dimensionamento diferente para prever de forma eficiente as resistências de falha distorcional desses pilares.

Guiado pelos dados de resistências última adquiridos através do estudo paramétrico realizado neste trabalho, foi considerada a proposta de Landesmann e Camotim (2013) descrita pela Eq. (4). A Figura $11\left(\mathrm{a}_{2}\right)$ relaciona esta proposta $\left(P_{n . D}^{*}\right)$ comparando-a com os resultados obtidos neste estudo. A Figura $12\left(b_{2}\right)$ mostra os valores correspondentes de $P_{u} / P_{n . D}^{*}$ versus $\bar{\lambda}_{D}$. Para esta proposta a média, o desvio padrão e os valores máximo e mínimo de $P_{u} / P_{n . D}^{*}$ são dados na Figura $11\left(\mathrm{~b}_{2}\right)$.

A curva sugerida por Landesmann e Camotim (2013) - Eq. (4) representa bem os resultados numéricos obtidos nesta pesquisa.

\section{Conclusões}

Este trabalho reportou uma investigação numérica (pelo método dos elementos finitos) sobre a influência da condição de suporte aparafusado no comportamento pós-crítico e no dimensionamento pelo MRD (Método da Resistência Direta) de pilares do tipo U enrijecido formadas a frio cujos modos de falha se deram por distorção.

Os pilares analisados exibiram extremidades aparafusadas, quinze geometrias de pilares em perfil $U$ enrijecido (variados comprimentos e dimensões de seção transversal) e diversos graus de aços foram considerados. Essas características foram cuidadosamente selecionadas para garantir que os pilares flambassem e falhassem no modo "puro" distorcional (i.e., evitando-se interação com o modo de flambagem local e/ou global) e cobrir uma extensão considerável de esbeltez (distorcional).

Os dados de resistência última adquiridos durante a análise paramétrica envolveram 138 pilares. Estes foram então usados para demonstrar que independentemente da 
geometria do pilar, a atual curva de dimensionamento à instabilidade distorcional do MRD não é capaz de prever adequadamente a resistência última de pilares tipo $U$ enrijecido com extremidades aparafusadas.

Com base nos resultados obtidos a partir do estudo paramétrico realizado, foi estudada a proposta de curva de dimensionamento à instabilidade distorcional sugerida por Landesmann e Camotim (2013). De fato, tal curva se correlacionou muito bem com os resultados numéricos obtidos neste trabalho.

\section{Agradecimentos}

O primeiro autor agradece o apoio financeiro da Vale S.A.

\section{Referências}

ASSOCIAÇÃO BRASILEIRA DE NORMAS TÉCNICAS, ABNT NBR 14762: Dimensionamento de estruturas de aço constituídas por perfis formados a frio. Rio de Janeiro, 2010.

AMERICAN IRON AND STEEL INSTITUTE, AISI-S100: Specification for the design of cold-formed steel structural members. Washington, D. C. 2016.

STANDARDS ASSOCIATION OF AUSTRALIA, AS/NZS 4600: Cold-Formed Steel Structures. North Sydney, 2005.

HANCOCK, Gregory J.; KNOW, Young.; BERNARD, Stefan. "Strength design curves for thin-walled sections undergoing distortional buckling". Journal of Constructional Steel Research, p. 169186, 1994.

LANDESMANN, Alexandre; CAMOTIM, Dinar. "On the Direct Strength (DSM) design of coldformed steel columns against distortional failure". Thin-Walled Structures, p. 168-187, 2013.

PHAM, Song Hong; PHAM, Cao Hung; HANCOCK, Gregory J. "Direct strength method of design for shear including sections with longitudinal web stiffeners". Thin-Walled Structures, p. 19-28, 2013.

RONDAL, J. "Cold-formed steel members and structures - General Report". Journal of Constructional Steel Research, p. 155-158, 2000.

SANTOS, Warlley Soares. On the strength and DSM design of end-bolted cold-formed steel columns buckling in distortional modes. DSc thesis, COPPE, Federal University of Rio de Janeiro, Rio de Janeiro, RJ, 2017.

SCHAFER, Benjamin W. "Computational modeling of cold-formed steel: characterizing geometric imperfections and residual stresses". Journal of Constructional Steel Research, p. 193-210, 1998.

SCHAFER, Benjamin W. Distortiosnal buckling of cold-formed steel columns. American Iron and Steel Institute (AISI) report, Washington DC, 2000.

SCHAFER, Benjamin W. "Review: The Direct Strength Method of cold-formed steel member design". Journal of Constructional Steel Research. p. 766-778, 2008.

SWANSON ANALYSIS SYSTEM INC. (SAS): Ansys Reference Manual (Vrs. 12), 2009.

$\mathrm{Yu}$, Chang; Panyanouvong, Mark Xouphab, "Bearing strength of cold-formed steel bolted connections with a gap," Thin-Walled Structures, p. 110-115, 2013. 